\title{
Percepção das gestantes sobre violência obstétrica no município de Pedro Afonso-TO
}

A violência obstétrica remete a um atendimento desumanizado, medicalização e uso de processos artificiais, tais atos que impactam no direito de escolha inclusive seus sentimentos e com isso afeta negativamente na qualidade de vida. As Unidades Básicas de Saúde (UBS) são porta de entrada para o pré-natal, com o objetivo de garantir a gestação de forma segura, este é o momento ideal para discussão de temas de interesse para a gestante. Tem como objetivo em identificar o conhecimento das gestantes sobre violência obstétrica no município de Pedro Afonso-TO. Trata-se de um estudo transversal, de metodologia quantitativa com uma amostra de trinta gestantes acompanhadas nas unidades básicas de saúde Tenente Salustiano e Pedro Zanina, os dados foram coletados através de um questionário semiestruturado. Após o preenchimento e obtenção dos relatórios gerados, os dados obtidos foram submetidos à análise estatística mais apropriada, após a coleta dos resultados. Em relação ao conhecimento sobre violência obstétrica $35 \%$ das gestantes não conheciam o termo e 17 \% acreditam ter sofrido violência obstétrica na última gestação. Aproximadamente $28 \%$ das gestantes relataram ter sofrido algum processo intervencionista durante o trabalho de parto e $80 \%$ delas afirmaram sobre a liberdade de mudança de posição sendo mais praticada no processo de parto. Esperou-se com esse estudo identificar o conhecimento das gestantes quanto à violência obstétrica, e a prevalência de atendimento desumanizado, maus tratos, intervenções desnecessárias. E buscamos saber se elas são respeitadas, tanto no bem-estar físico e emocional e sobre sua autonomia.

Palavras-chave: Gestantes; Violência Obstétrica; Unidade Básica de Saúde.

\section{Pregnant women's perception of obstric violence in the city of Pedro Afonso-TO}

Obstetric violence refers to dehumanized care, medicalization and use of artificial processes, such acts that impact on the right of choice and even their feeling and with this affects the quality of life negatively. The Basic Health Units (UBS) are the gateway to prenatal care, in order to ensure safe pregnancy, this is the ideal moment to discuss topics of interest to pregnant women. Identify the knowledge of pregnant women about obstetric violence in the municipality of Pedro Afonso-TO. This is a cross-sectional study of quantitative methodology with a sample of thirty pregnant women followed at the basic health units Lieutenant Salustiano and Pedro Zanina, the data will be collected through a semi-structured questionnaire. After completing and obtaining the generated reports, the obtained data will be submitted to a more appropriate statistical analysis after the results collection. About the knowledge about obstetric violence $35 \%$ pregnant women did not know the term and $17 \%$ believe they suffered obstetric violence in the last pregnancy. Approximately $28 \%$ reported having suffered some interventionist process and the freedom of change of position being more practiced in the process of delivery $80 \%$. It is expected with this study to identify the knowledge of pregnant women regarding obstetric violence, and the prevalence of dehumanized care, abuse, unnecessary interventions. And seeks to know if they are respected, both in terms of physical and emotional well-being and their autonomy.

Keywords: Obstetric Violence; Pregnant Women; Basic Health Unit.

Reviewed anonymously in the process of blind peer.

Ana Karoline Soares Costa Faculdade Guaraí, Brasi http://lattes.cnpq.br/8277187410798539 annakaroline70@hotmail.com

Myllena Coelho Fernandes

Faculdade Guaraí, Brasil

http://lattes.cnpq.br/6018353948786590

myllena.c.fernandes@gmail.com

Glaucya Wanderley Santos Markus

Faculdade Guaraí, Brasil

http://lattes.cnpq.br/5568510365985231

glaucyamarkus@outlook.com
Juliane Marcelino dos Santos

Faculdade Guaraí, Brasi

http://lattes.cnpq.br/8751832120632358

ulianemarcelino@hotmail.com

Giullia Bianca Ferraciolli do Couto

Faculdade Guaraí, Brasil

http://lattes.cnpq.br/0109560699727614

giulliabianca@hotmail.com

Reobbe Aguiar Pereira

Faculdade Guaraí, Brasil

http://lattes.cnpq.br/7447115724350334

enfreobbe@gmail.com
Karla Camila Correia da Silva

Faculdade Guaraí, Brasil

http://lattes.cnpq.br/1981447087125364

karlacamilac@yahoo.com.br

Adriana Keila Dias

Faculdade Guaraí, Brasil

http://lattes.cnpq.br/2128882976477548

adrianakeiladias@hotmail.com
Referencing this:

COSTA, A. K. S.; FERNANDES, M. C.; MARKUS, G. W. S.; SANTOS, J. M.; COUTO, G. B. F.; PEREIRA, R. A.; SILVA, K. C. C.; DIAS, A. K.. Percepção das gestantes sobre violência obstétrica no município de Pedro Afonso-TO. Scire Salutis, v.11, n.3, p.69-79, 2021. DOI: http://doi.org/10.6008/CBPC2236-9600.2021.003.0010 


\section{INTRODUÇÃO}

A violência obstétrica é definida como apoderação por partes dos profissionais da saúde sobre o corpo da mulher e do seu processo reprodutivo, afligindo assim fisicamente ou psicologicamente com intervenções desumanizadas, patologização dos processos naturais, abuso de medicação, tirando da mulher a autonomia e a capacidade de decidir livremente sobre seu corpo e sexualidade, atingindo negativamente na sua qualidade de vida (APOLINÁRIO et al., 2016).

Ao descobrir uma gestação a mulher passa por uma transição de preparação e adaptação para chegada de um novo ser. Durante o pré-natal ela deve ser orientada sobre todas as mudanças fisiológicas da gestação, e sobre o todo trabalho de parto, expulsão e puerpério (SILVA et al., 2017; OMS, 2014). A violência obstétrica remete a um atendimento desumanizado, medicalização e uso de processos artificiais, tais atos que impactam no direito de escolha e inclusive seus sentimentos e com isso afeta negativamente na qualidade de vida (OMS, 2014). Essas violências são um agrupamento de vários tipos de agressões à mulher, que causam danos à saúde e está presente em todo o mundo, sem discriminação social, racial, etária ou religiosa, um fenômeno decorrente grave que se expande, violado mesmo após os avanços sociais e os direitos estabelecidos pela lei (SOUZA, 2014).

A repercussão e consequências futuras que esse tipo de violência traz na vida das mulheres, tornase assunto delicado e de grande importância, deve se ter uma atenção maior, oferecendo a essas mulheres conhecimentos de seus direitos, por mais que não tenha uma lei específica para esse tipo de violência, é amparada por outras leis relacionadas à violência (GOMES et al., 2015). Nacionalmente existe o projeto de lei no 7633/2014, que dispõe sobre a humanização da assistência à mulher no trabalho de parto e ao neonato (BOHREN et al., 2015). Atualmente, em nosso país, apenas no Estado de Santa Catarina, dispõe a lei no 17.097, contra violência obstétrica (OMS, 2016).

Em conformidade com o art. da Lei Federal no 11.108, de 07 de abril de 2005, mais compreendida como a Lei do Acompanhante, ordenam os sistemas de saúde do Sistema Único de Saúde (SUS), da rede conveniada ou própria, estão impostos a conceder à gestante o direito de um acompanhante durante toda a fase do trabalho de parto e no puerpério. Direito permitido pela lei, e o descumprimento de tal, torna-se uma violação dos direitos (BRASIL, 2017).

A violência obstétrica tornou-se conhecida mundialmente a partir do final da década de 1950, depois que foi publicada a matéria intitulada "a crueldade nas maternidades" por uma revista nos Estados Unidos da América. Como tratamentos desumanos, violentos e grosseiros, recebido por muitas mulheres no referido país. No Brasil, a temática passou a ser pesquisada no meio acadêmico apenas na década de 1980 e seguidamente por participantes dos movimentos feministas, que passaram a descrever explicitamente o parto institucionalizado como violência obstétrica (DINIZ et al., 2015).

No Brasil, a criação da Rede pela Humanização do Parto e do Nascimento (ReHuNa), em 1993, e do Programa de Humanização no Pré-Natal e Nascimento (PHPN), em 2000. Esses programas visam atender a especificidade de cada mulher, e principalmente no processo de parturição, com o intuito de minimizar intervenções desnecessárias e inapropriadas ao parto, buscando a humanização do ciclo gravídico- 
puerperal (ESCOBAL et al., 2016).

Ministério da Saúde, em maio de 2004 o lançou a Política Nacional de Atenção Integral à Saúde da Mulher- Princípios de Diretrizes, construída a partir da proposta do SUS e cumprindo as características da nova política de saúde (RODRIGUES et al., 2015; BRASIL, 2017; ESCOBAL et al., 2016).

O foco da Atenção Obstétrica é a qualificação do pré-natal, parto/ nascimento, puerpério e ao abortamento e a diminuição da mortalidade entre binômio. Essa qualidade da atenção do período do trabalho de parto e ao nascer foi uma mudança do modelo de cuidado prevalecente no país, uma adoção de boas práticas (baseadas em evidências científicas/OMS), a garantir os direitos das mulheres e dos bebês, a inclusão das obstetrizes e enfermeiras obstétricas, especialmente na atenção ao parto de baixo risco (BARBOZA et al., 2016; PEREIRA et al., 2016; GALLO et al., 2011).

As Unidades Básicas de Saúde (UBS) são portas de entrada para o pré-natal, com o objetivo de garantir a gestação de forma segura. A Rede Cegonha com o programa do processo de reprodução e a importância da atenção humanizada à gravidez ao parto e puerpério (pós-parto), de modo que os neonatos têm o direito ao nascimento protegido e ao acompanhamento do desenvolvimento saudável (LEMES et al., 2015; GOMES et al., 2015; BRASIL, 2019). Foi possível identificar na literatura que violência obstétrica é um problema vivenciado por muitas mulheres, precisa-se de mais estudos relacionados a este assunto, com intuito de enriquecer os conhecimentos acerca da violência obstétrica.

Pouco conhecimento da gestante sobre violência obstétrica, que a torna vulnerável a situação ou condição. Frente ao exposto surgiu o questionamento: Qual a percepção das gestantes sobre violência obstétrica? E quais as implicações desse conhecimento? A problemática desse estudo ressalta a precarização do sistema de saúde, devido a poucas aplicações de investimento nas maternidades na atuação desrespeitosa e a falta de ética dos profissionais. As consequências que essa escassez leva à vida das mulheres afeta diretamente na qualidade de vida futura. E devido as orientações insuficientes sobre o período gestacional em sua magnitude durante o pré-natal. A vista disso objetivou-se com este artigo identificar o conhecimento das gestantes sobre violência obstétrica no município de Pedro Afonso-TO. Foi evidente que essa prática não é recorrente no sistema de saúde do município.

\section{METODOLOGIA}

Este estudo propôs a realização de uma pesquisa de campo, de modelo transversal, de metodologia quantitativa, no qual os dados foram coletados a partir de um questionário semiestruturado desenvolvido pelas pesquisadoras, baseado em artigo sobre violência obstétrica. A pesquisa foi realizada com gestantes que realizam pré-natal nas UBS, no município de Pedro Afonso - TO. A população do estudo foi composta por 15 gestantes da Unidade Básica de Saúde Tenente Salustiano e 15 gestantes Unidade Básica de Saúde Pedro Zanina.

Os dados foram coletados no dia 20 de outubro ao dia 28 de novembro de 2019, no horário de funcionamento das unidades básicas de saúde, a mostra foi de 30 gestantes. Critérios de inclusão o fato de ser secundigestas cadastradas no SISPRENATAL (Sistema de Acompanhamento do Programa de 
Humanização no Pré-Natal e Nascimento) e que aceitaram a participar da pesquisa mediante a assinatura do termo de Consentimento Livre e Esclarecido (TCLE), e como critérios de exclusão, mulheres uníparas, ou com aborto em única gestação anterior, ou que e não aceitarem a participar da pesquisa por se sentir inábeis a responder o questionário proposto pelo estudo.

A pesquisa foi realizada com autorização pelo secretário de saúde do município de Pedro Afonso TO, levando-se em consideração os aspectos éticos em pesquisas que envolvem seres humanos, conforme descrito na Resolução $n^{\circ}$ 466/2012, do Conselho Nacional de Saúde (CNS), que regulamenta a pesquisa envolvendo seres humanos. A pesquisa obteve a aprovação do Comitê de Ética em Pesquisa do Centro Universitário Luterano de Palmas - ULBRA, sob o parecer № 4.214.024.

\section{RESULTADOS E DISCUSSÃO}

A pesquisa contou com 30 mulheres, que realizavam atendimento de pré-natal nas UBS do município de Pedro Afonso- TO. Os resultados encontrados foram sistematizados, estruturados em gráficos e tabelas e analisados diante a literatura. A tabela 01 refere-se à classificação numérica e percentual da faixa etária, estado civil, escolaridade, cor e religião.

Tabela 1: Caracterização sociodemográfica das participantes do estudo (N=30), Pedro Afonso-TO, 2019.

\begin{tabular}{|c|c|c|c|c|}
\hline Características Sociodemográficas & Especificações & $\mathbf{N}$ & & \\
\hline \multirow[t]{2}{*}{ Faixa etária } & 19 á 29 & & 16 & $53,3 \%$ \\
\hline & 30 á 39 & & 14 & $47 \%$ \\
\hline \multirow[t]{3}{*}{ Estado Civil } & Casada & & 18 & $60 \%$ \\
\hline & Solteira & & 12 & $40 \%$ \\
\hline & Divorciada & & 0 & $0 \%$ \\
\hline \multirow[t]{5}{*}{ Escolaridade } & Ens. Méd. Completo & & 23 & $77 \%$ \\
\hline & Ens. Méd. Incompleto & & 2 & $7 \%$ \\
\hline & Ens. Fund. Incompleto & & 1 & $3,3 \%$ \\
\hline & Ens. Sup. Completo & & 2 & $7 \%$ \\
\hline & Ens. Sup. Incompleto & & 2 & $7 \%$ \\
\hline \multirow[t]{5}{*}{ Cor } & Branca & & 2 & $7 \%$ \\
\hline & Preta & & 0 & $0 \%$ \\
\hline & Parda & & 28 & $93,3 \%$ \\
\hline & Amarela & & 0 & $0 \%$ \\
\hline & Indígena & & 0 & $0 \%$ \\
\hline \multirow[t]{2}{*}{ Religião } & Católica & & 21 & $70 \%$ \\
\hline & Evangélica & & 9 & $30 \%$ \\
\hline TOTAL & - & & 30 & $100 \%$ \\
\hline
\end{tabular}

Analisando a tabela 01, observa-se que o índice encontrado em relação à faixa etária são mulheres de 19 a 29 (53,3\%), sendo essa idade a mais apropriada para a escolha de ser mãe, e acreditamos que venha influenciar na pouca experiência e no conhecimento a respeito da importância com os cuidados com a saúde e na cooperação na gestação e no parto, como também o entendimento sobre violência obstétrica (MEDEIROS et al., 2016).

Por outro lado, visando quase a metade do grupo entrevistado, 14 (47\%) de 30 a 39 anos, segundo um estudo feito pelo Instituto Brasileiro de Geografia e Estatística (IBGE) tem tido um aumento de nascimentos de mães com essa faixa, e está relacionado com rejuvenescimento, dar à luz é saúde, devido a quantidade de hormônios liberados e cita sobre a maternidade que vem com maturidade, acredita-se que o conhecimento sobre seus direitos sejam prováveis (TADEU, 2016). 
Quanto aos dados referentes ao estado civil percebe-se que a maioria das entrevistadas é casada, 18 (60\%). E com isso a prevalência de sofrimento de violência obstétrica diminui por ter o companheiro no momento do parto é importante para um vínculo afetivo. E as outras 12 (40\%) relataram serem mães solteiras, tendo em vista que o estado civil das mulheres serem solteiras, a falta do companheiro em um momento tão esperado pode gerar algum desconforto. A paternidade contribui melhor para a ligação afetuosa entre ambos. Para as gestantes, esse momento de maternidade é tão importante e vital em sua vida, e quando se trata da qualidade da assistência a ser prestada, não deveria existir distinção de classe social, estado civil, raça e idade, no entanto, existem indicativos científicos que evidenciam que o aceso a saúde é constantemente afetado por questões de interseccionalidade, tornando assim, para determinadas mulheres uma aquisição precária do que as outras (FABIANA, 2019).

Com relação ao nível de escolaridade, percebe-se que o maior índice encontrado foi de mulheres com o ensino médio completo 23 (80\%). O nível de escolaridade pode favorecer positivamente para o entendimento acerca da gestação, trabalho de parto e parto, e mediante da apropriada compreensão de todo processo gravídico-puerperal. O nível de escolaridade pode ainda, dificultar ou facilitar a interpretação de intervenções abusivas e o que é de fato natural (MEDEIROS et al., 2016). A respeito da cor, foram notados que a maioria é de cor parda 28 (93,3\%) alguns estudos brasileiros afirmam a discriminação de mulheres na assistência ao parto são as mais pobres e as negras como a peregrinação em busca de leito hospitalar, e ao menor uso de anestesia no momento do parto (LEAL et al., 2005).

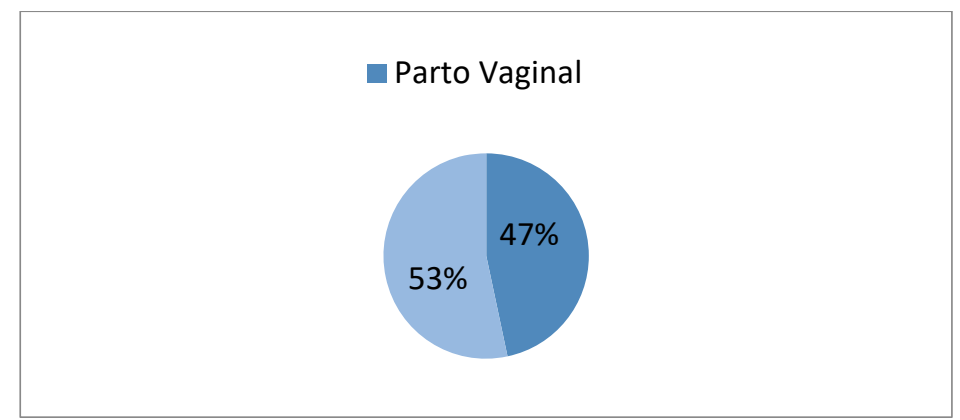

Gráfico 1: Distribuição da amostra quando questionadas sobre a preferência da via de parto. (N=30), Pedro Afonso TO, 2019

Analisando o gráfico 01, nota-se pouca diferença entre as escolhas de via de parto, apesar de o parto cesáreo apresentar-se maior com (53\%), Mesmo estas sendo submetidas ao parto cesariana, a maioria relatou por medo de sentir dor, por orientação médica, evitar deformações na vagina, pela recuperação mais rápida ou para laquear. Segundo um estudo realizado as razões para considerarem o melhor meio de nascimento estão relacionados principalmente pela ausência de dores de trabalho de parto, impossibilitar-se de sentir medo do parto, aproveitar a via para realização de laqueadura, pelo procedimento ser mais rápido, e também muitas vezes salvar a vida do bebê, além de dispor de esclarecimentos sobre o processo e por ter controle sobre o acontecimento, para se tornar uma experiência agradável e a garantia de poder desfrutar com segurança do bebê (PESSOA et al., 2016).

Já no que se diz a escolha da via de parto vaginal (47\%), relataram medo à anestesia, pela recuperação ser mais rápida, ou ser habitual de família. Para elas a vivência do seu protagonismo e a 
grande satisfação de poder acompanhar cada momento da cena de parto, como um processo fisiológico, por ser algo mais natural a saudável para ela e seu bebê (PESSOA et al., 2016).

Tabela 2: Distribuição da amostra quando questionadas sobre o conhecimento de violência obstétrica. ( $N=30)$, Pedro Afonso - TO, 2019

\begin{tabular}{|c|c|c|c|}
\hline Perguntas & & $\mathbf{N}$ & $(\%)$ \\
\hline \multirow[t]{2}{*}{ Você sabe o que é violência obstétrica? } & Sim & 19 & $63,3 \%$ \\
\hline & Não & 11 & $35 \%$ \\
\hline \multirow[t]{2}{*}{ Último parto realizado em: } & Maternidade pública & 25 & $83,3 \%$ \\
\hline & Maternidade privada & 5 & $17 \%$ \\
\hline \multirow[t]{3}{*}{ Na última gestação acredita que sofreu violência obstétrica? } & Sim & 5 & $17 \%$ \\
\hline & Não & 19 & $63,3 \%$ \\
\hline & Não sei & 6 & $20 \%$ \\
\hline
\end{tabular}

Analisando a tabela 02, nota-se que a maioria das entrevistadas 19 (63,3\%) relatou saber o que é violência obstétrica. Perante as perguntas sobre violência obstétrica no questionário, percebe-se a falta de conhecimento do mesmo. Por outro grupo responderam não saber o que é a violência obstétrica 11 (35\%). A violência obstétrica pode ser ainda pouco reconhecida. E para as mulheres durante o trabalho de parto, onde estão vivenciando fortes emoções, e adaptações, um momento muito delicado, e ao mesmo tempo ocorrem atos abusivos e violentos as mesmas, que por vezes fazem calar-se diante da condição (PESSOA et al., 2016).

Durante a gestação é onde a mulher deve ser informada sobre seus direitos, no trabalho de parto, parto e pós-parto, durante as consultas de pré-natal, momento que favorece para serem abordados assuntos variados, serem instruída quanto à autonomia e tomada de decisões do que remete ao seu corpo e sua parturição, onde ela pode se manifestar, argumentar, e que possa denunciar situações de maus tratos e desrespeito com ela. Com base na análise do tipo de maternidade que realizaram o último parto 25 $(83,3 \%)$ relataram ter tido em pública, e $5(17 \%)$ em maternidade privada. Diante a pesquisa pode notar que não importa a forma de unidade, sendo privada ou pública, a prática de violência está ligada a humanização dos profissionais da saúde.

Diante o questionamento sobre na última gestação ter sofrido violência obstétrica, pode notar que a maioria das entrevistadas responderam não ter sofrido $19(63,3 \%)$ delas $5(17 \%)$ relataram ter sofrido violência e 6 (20\%) não saber responder se ocorreu. Não foram encontradas altas taxas de desconhecimento sobre ter sofrido. Um fator contribuinte para perpetuação do desconhecimento é devido à pouca divulgação sobre atos que são considerados violência obstétrica pelos serviços de saúde, visto que elas são institucionalizadas nas maternidades (CUNHA et al., 2017).

Tabela 3: Distribuição da amostra quando questionadas quanto a violências obstétricas. ( $N=30)$, Pedro Afonso-TO, 2019

\begin{tabular}{|c|c|c|c|}
\hline Perguntas & & $\mathbf{N}$ & $(\%)$ \\
\hline \multirow[t]{2}{*}{ Se sentiu devidamente informada sobre os procedimentos que foram realizados? } & Sim & 17 & $57 \%$ \\
\hline & Não & 13 & $43,3 \%$ \\
\hline \multirow[t]{2}{*}{ Responderam suas perguntas adequadamente? } & Sim & 22 & $73,3 \%$ \\
\hline & Não & 8 & $27 \%$ \\
\hline \multirow[t]{2}{*}{ Se sentiu discriminada ou maltratada verbalmente? (Tratamento grosseiro, ameaça, gritos, reprimiram ou humilhações) } & Sim & 5 & $17 \%$ \\
\hline & Não & 25 & $83,3 \%$ \\
\hline \multirow[t]{2}{*}{ Se sentiu maltratada fisicamente? } & Sim & 3 & $10 \%$ \\
\hline & Não & 27 & $90 \%$ \\
\hline
\end{tabular}




\begin{tabular}{|c|c|c|c|}
\hline \multirow[t]{2}{*}{ Teve direito a acompanhante? } & Sim & 25 & $83,3 \%$ \\
\hline & Não & 5 & $17 \%$ \\
\hline \multirow[t]{2}{*}{ Foi oferecida alguma técnica para aliviar à dor? (Massagens, óleos, medicamentos)? } & $\operatorname{Sim}$ & 13 & $43,3 \%$ \\
\hline & Não & 17 & $57 \%$ \\
\hline \multirow[t]{2}{*}{ Se sentiu abandonada, com medo ou angústia? } & $\operatorname{Sim}$ & 7 & $23,3 \%$ \\
\hline & Não & 23 & $77 \%$ \\
\hline \multirow[t]{2}{*}{ Pôde se alimentar e/ou ingerir líquidos? } & Sim & 15 & $50 \%$ \\
\hline & Não & 15 & $50 \%$ \\
\hline \multirow[t]{2}{*}{ Teve liberdade para se movimentar? } & Sim & 26 & $87 \%$ \\
\hline & Não & 4 & $13,3 \%$ \\
\hline \multirow[t]{2}{*}{ Foi amarrada? } & Sim & 2 & $7 \%$ \\
\hline & Não & 28 & $93,3 \%$ \\
\hline \multirow[t]{2}{*}{ O exame de toque foi em algum momento desrespeitoso, doloroso ou a deixou exposta de maneira inadequada? } & Sim & 4 & $13,3 \%$ \\
\hline & Não & 26 & $87 \%$ \\
\hline \multirow[t]{2}{*}{$\begin{array}{l}\text { Foi incentivada a ficar em outras posições além da posição tradicional de trabalho de parto (deitada de costas, com as } \\
\text { pernas dobradas e afastadas)? }\end{array}$} & Sim & 6 & $20 \%$ \\
\hline & Não & 24 & $80 \%$ \\
\hline
\end{tabular}

De acordo a tabela 03, percebe-se quando interrogadas sobre as informações adequadas dos procedimentos que foram realizados 17 (57\%) responderam sim, em quanto outro grupo de 13 (43,3\%) delas relatou não ser informadas. Alguns estudos mostram que a humanização do parto é a chave para não ocorrência de violências, tendo como respeito a mulher como pessoa única, especialmente em um momento de sensibilidade como o parto, humanizar também é manter um diálogo, conversar e prestar informações claras a mulher sobre os procedimentos que serão realizados em seu corpo, e pedir sua autorização para realiza-los e explicar a finalidade de cada intervenção, de seus riscos e outras possíveis alternativas se a elas não forem cabíveis (IBGE, 2017).

Aos dados sobre o sentimento de discriminada ou maltratada verbalmente tratamento grosseiro, ameaça, gritos, reprimiram ou humilhações, 25 (83,3\%) responderam que não e $5(17 \%)$ confirmaram ter sofrido. Pode observar que as mulheres que responderam saber sobre violência obstétrica tinham base sobre o assunto, porem ser ter a noção da abrangência dessa prática, o obstáculo frente a essas ocorrências são a falta de busca de informações ativa das gestantes com os profissionais que as atendem.

A Organização Mundial de Saúde (OMS) assegura como maus tratos e abuso a assistência à saúde da mulher no processo reprodutivo, gestação e puerpério, envolvendo todas as ações de descaso, negligência, desrespeito, abuso verbal, físico, sexual, psicológico, ou qualquer ação que gera descontentamento com o serviço de saúde como grave violação dos direitos humanos básicos (LEAL et al., 2005).

De acordo o questionamento sobre técnica oferecida para o alívio da dor $13(43,3 \%)$ respondeu que sim, enquanto 17 (57\%) responderam não. Percebe-se que a maioria das entrevistadas relatou não ter recebido nenhum método de alívio para dor no trabalho de parto. Para algumas mulheres o alívio pode ser alcançado apenas com suporte físico e emocional adequado, porem existe métodos como massagens, óleos, medicamentos, banho de chuveiro, deambulação ativa, utilização de bolas de nascimento, toques confortantes, entre outras medidas. A presença de um familiar pode afetar positivamente para diminuição da intensidade dolorosa (PESSOA et al., 2016). Sobre poder se alimentar e ingerir líquidos 15 (50\%) 
respondeu sim e 15 (50\%) que não. As mulheres que relataram não ter se alimentado durante o trabalho de parto, ficaram muito tempo sentindo fome e sede e consecutivamente não tinham disposição para contribuir no momento do parto.

No que se trata de alimentar-se durante o trabalho de parto, é uma indagação ainda muito abordada na assistência obstétrica. A OMS e a Rede cegonha preconizam a ingesta de alimentos líquidos e sólidos leves durante o trabalho de parto, sendo esta prática um dos exemplos no que se diz respeito a autonomia da mulher. A restrição de ingesta líquida e alimentar no momento do trabalho de parto até este momento fazem parte de rotina de obstétrica e anestésica (APOLINÁRIO et al., 2016).

Quando questionadas quanto se teve liberdade para movimentar-se se nota quantidade pequena dentre as entrevistadas $26(87 \%)$ respondeu sim e 4 (13,3\%). Diante um estudo realizado não há posição completamente perfeita ou adequada para as mulheres no trabalho de parto, porem para a equipe que as assiste, classifica como conveniente a eles pelo acompanhamento, sendo de preferência das mulheres deambular, preferencialmente no que se inicia. Durante muito tempo as mulheres eram orientadas a ficarem deitadas, restritas ao leito e ainda diriam que a deambulação não influenciara a probabilidade de cesariana. Hoje existem estudos que comprovam que a posição supina no primeiro período de trabalho de parto pode trazer efeitos fisiológicos adversos a mãe e o bebê (PESSOA et al., 2016).

Perante as respostas das mulheres entrevistadas, quanto ao exame de toque ter sido desrespeitoso, doloroso ou a deixou exposta de maneira inadequada 26 (87\%) relatou não ter sofrido, e 4 $(13,3 \%)$ relataram desconforto, constrangimento, de forma abusiva e dolorosa. Segundo estudos, a quantidade de exame de toque vaginal deve ser realizada conforme avaliação e conforto, no tempo certo de verificação, e desde que seja do consentimento e permitido pela gestante, para que se tenha uma análise adequada do processo de trabalho de parto. As maternidades e hospitais por serem campo de formação acadêmica, provoca aumento da realização dessa prática, mesmo não sendo preconizado (APOLINÁRIO et al., 2016).

O Ministério da Saúde tem intuito de promover humanização incentivando os profissionais praticar o mesmo nas maternidades, agindo com promoção da saúde, promover ambiente acolhedor e diminuir rotinas que implicam diretamente com o isolamento imposto à mulher. Aplicar procedimentos e medidas benéficas para o acompanhamento do parto e nascimento, com fins de diminuir riscos para a mãe e bebê, evitando práticas rotineiras desnecessárias e institucionalizadas, que não trazem benefícios para ambos (IBGE, 2016).

Lei do Acompanhante

- Sim Não

$33 \%$

Gráfico 2: Distribuição dos dados quando interrogadas sobre o conhecimento da lei do acompanhante. ( $N=30), P e d r o$ Afonso-TO, 2019. 
Analisando o gráfico 02 , notou-se que a maioria das entrevistadas relatou ter tido direito ao acompanhante $(67 \%)$ e menor parte de (33\%) relataram não ter possuído. Diante dos relatos durante a pesquisa pode - se perceber que as que não tiveram o direito de escolha do acompanhante, os trouxe medo e a insegurança, desmotivando-as para desenvoltura no momento de trabalho de parto, a presença de uma pessoa conhecida como acompanhante contribui para minoração de intervenções medicamentosas, podendo relacionado também com o alivio da dor, e aumentar o vínculo afetivo entre a mãe-bebê.

Com isso, em conformidade com o art. 10 da Lei 11.108, 7 de abril de 2005, permite a presença de acompanhante de escolha da mulher em trabalho de parto, parto e pós-parto imediato as instituições públicas e conveniados com o Sistema Único de Saúde (SUS), sendo um direito resguardado pela lei, e ao descumprimento desta, transfigura-se violação dos direitos das mulheres (BRASIL, 2017). Observou-se que mesmo com a existência de uma lei que ampare esse direito, as unidades hospitalares não realizam essa prática, o direito de escolha de acompanhante em todo seu período de permanência hospitalar, deixandoas inseguras, com medo do desconhecido, vulneráveis às intervenções profissionais e as relações de desigualdades, podendo trazer danos inconvertíveis a sua saúde e do seu bebê.

\section{CONCLUSÕES}

No que se reconhece como violência obstétrica, pode se observar que tal violência foi citada em suas diversas formas, desde a negligência na assistência, e em todo o processo parturitivo, negativa de informações esclarecedoras de diagnóstico, seu bem estar físico, psicológico, autonomia e agressões verbais.

Foi observado nesse estudo que a grande maioria das gestantes disse ter conhecimento acerca da violência obstétrica e que um pequeno grupo respondeu não saber o que é, porém pode se observar que algumas sofreram violência como não oferecer alguma técnica para aliviar à dor como massagens, óleos, medicamentos, como não saber da lei do acompanhante. Em relação ao direito de acompanhante assegurado pela lei no 11.108 de 2005 percebeu- se que houve uma quantidade considerável que não tiveram o direito de escolha. Considerando o estudo observa-se que a assistência da mulher no período gravídico e puerperal no Brasil está focada no modelo biomédico, que fraciona o ser humano, contribuindo assim para o aumento de procedimentos intervencionistas e invasivos durante o trabalho de parto. Tornase necessário uma melhor discussão sobre violência obstétrica, inclusive uma especificação de lei.

Diante do exposto é necessário capacitação dos profissionais de saúde para promover uma assistência humanizada e adequada para o cuidado à saúde da mulher, e o aumento de pesquisas com gestantes acompanhadas na atenção primária devem ser realizadas, uma vez que este é o local onde as gestantes primeiramente se inserem no sistema de saúde. Fazem-se fundamentais estudos que abordem essa temática violência obstétrica afim para conceder autoridade à mulher por meio do conhecimento para que ela seja a protagonista do seu parto tendo conhecimento sobre definições formas de denúncias, leis, afim que ela possa garantir seus direitos legais. 


\section{REFERÊNCIAS}

APOLINÁRIO, D.; RABELO, M.; WOLFF, L. D. G.; SOUZA, S. R. R. K.; LEAL, G. C. G.. Práticas na atenção ao parto e nascimento sob a perspectiva das puérperas. Rev Rene, v.17, n.1, p.20-80, 2016

BARBOZA, L. P.; MOTA, A.. Violência obstétrica: vivências de sofrimento entre gestantes do Brasil. Revista Psicologia, Diversidade e Saúde, v.5, n.1, p.119-129, 2016.

BOHREN, M. A.; VOGEL, J. P.; HUNTER, E. C.. The mistreatment of women during childbirth in health facilities globally: a mixed-methods systematic review. PLOS Med., v.12, n.6, p.1-32, 2015.

BRASIL. Ministério da Saúde. Saúde da Mulher. Ministério da Saúde, 2013.

BRASIL. Lei 11108/2006. Garante às parturientes o direito à presença de acompanhante durante o trabalho de parto, parto e pós-parto imediato, no âmbito do Sistema Único de Saúde - SUS. Brasília: DOU, 2005.

CUNHA, F. A.. Violência obstétrica no processo de parturição em maternidades vinculadas à Rede Cegonha. Reprod Clim, 2017.

DINIZ, S. G.; SALGADO, H. O.; ANDREZZO, H. F. A.. Abuse and disrespect in childbirth care as a public health issue in Brazil: origins, definitions, impacts on maternal health, and proposals for its prevention. Hum. Growth Dev., v.25, n.3, p.377-384, 2015.

ESCOBAL, A. P. L.; SOARES, M. C.; MEINCKE, S. M. K.; KERBER, N. P. C.; SANTOS, C. P.; MATOS, G. C.. Experiências das puérperas adolescentes no processo de parturição. Rev. Fund. Care, v.8, n.3, 2016.

FABIANA, P.. A importância do direito ao acompanhante para prevenir a violência obstétrica. 2019.

GALLO, R. B. S.; SANTANA, L. S.; MARCOLLIN, A. C.; FERREIRA, C. H. J.; DUARTE, A.; QUINTANA, S. M.. Recursos não farmacológicos no trabalho de parto. Protocolo Assistencial, v.39, n.1, p.41-80, 2011.

GOMES, P. R. F.; KUNZLER, I. M.. Violência Obstétrica E Relações De Poder No Parto. Revista Salão do Conhecimento, Unijuí, 2015.

IBGE. Instituto Brasileiro de Geografia e Estatistica. Mulheres que têm gravidez tardia vivem mais tempo, IBGE aponta que nascimentos com mães de $\mathbf{3 0}$ a $\mathbf{3 9}$ anos aumentaram, 2016.
LEAL, M. C.; GAMA, S. G. N.; CUNHA, C. B.. Desigualdades raciais, sociodemográficas e na assistência ao pré-natal e ao parto. Rev. Saúde Pública, v.39, n.1, p.100-107, 2005.

LEAL, M. C.; GAMA, S. G. N.; CUNHA, C. B.. Desigualdades raciais, sociodemográficas e na assistência ao pré-natal e ao parto. Ver. Saude Publica, v.39, n.1, p.100-107, 2014.

LEMES, C. M.; OLIVEIRA, D. M.; OLIVEIRA, M. J. P.. Percepção das Puérperas em relação à indução do parto. Rev. Fac. Ciênc. Méd., v.17, n.2, p.86-91, 2015.

MEDEIROS, N. C. M.; MARTINS, E. N. X.; CABOIM, F. E. F; PALMEIRA, M. N. F. A. L.. Violência Obstétrica: percepções acerca do parto normal. Rev. Tem em Saúde, v.16, n.3, 2016

OMS. Organização Mundial da Saúde. Recomendações da OMS sobre cuidados pré-natais para uma experiência positiva na gravidez, 2016.

OMS. Organização Mundial da Saúde. Prevenção e eliminação de abusos, desrespeito e maus-tratos durante o parto em instituições de saúde. Genebra: OMS, 2014.

PEREIRA, J. S.; SILVA, J. C. O.; BORGES, N. A.; RIBEIRO, M. M. G.; AUREK, L. J.; SOUZA, J. H. K.. Violência obstétrica: Ofensa à dignidade humana. Brazilian Journal of Surgery and Clinical Research, v.15, n.1, p.103-108, 2016.

PESSOA, L. M.; BARBOSA, A. B. A.; RODRIGUES, E. S. R. C.; LIMA, T. N. F. A.. Conhecimento da puérpera acerca da violência obstétrica. Rev. Tema em Saúde, v.16, n.4, 2016.

RODRIGUES, D. P.; ALVES, V. H.; PENNA, L. H. G.. A peregrinação no período reprodutivo: uma violência no campo obstétrico. Esc. Anna Nery, v.19, n.4, 2015.

SADLER, M.; SANTOS, M. J.; RUIZ-BERDÚN, D.; ROJAS, G. L.; SKOKO, E.. Moving beyond disrespect and abuse: addressing the structural dimensions of obstetric violence. Reprod Health Matters, 2016.

SILVA, T. S.; MELO, R. O.; SODRÉ, M. P.. MOREIRA, R. C. R.; SOUZA, Z. C. S. N.. A extensão universitária e a prevenção da violência obstétrica. Revista Ciência em Extensão, v.13, n.1, p.176-189, 2017.

SOUZA, K. J.. Violência institucional na atenção obstétrica: proposta de modelo preditivo para a depressão pós-parto. 2014.

TADEU, R.. Mulheres que têm gravidez tardia vivem mais tempo: IBGE aponta que nascimentos com mães de 30 a 39 anos aumentaram, 2016.

A CBPC - Companhia Brasileira de Produção Científica (CNPJ: 11.221.422/0001-03) detém os direitos materiais desta publicação. Os direitos referem-se à publicação do trabalho em qualquer parte do mundo, incluindo os direitos às renovações, expansões e disseminações da contribuição, bem como outros direitos subsidiários. Todos os trabalhos publicados eletronicamente poderão posteriormente ser publicados em coletâneas impressas sob coordenação da Sustenere Publishing, da Companhia Brasileira de Produção Científica e seus parceiros autorizados. Os (as) autores (as) preservam os direitos autorais, mas não têm permissão para a publicação da contribuição em outro meio, impresso ou digital, em português ou em tradução. 